\title{
Emergency response in a rapidly changing Arctic
}

\author{
Dylan G. Clark MSc CCP, James D. Ford PhD
}

Cite as: CMAJ 2017 January 30;189:E135-6. doi: 10.1503/cmaj.161085

$\mathbf{E}$ mergency response capacity in the Canadian North was in the national spotlight in the summer of 2016 as the largest cruise ship to date, the Crystal Serenity, navigated from Alaska to New York via the Northwest Passage. The journey raised concerns about Canada's capacity to respond to any large-scale disaster in the Arctic given limited infrastructure and the challenges of remoteness. ${ }^{1}$ Indeed, in 2010, the Clipper Adventurer ran aground about $100 \mathrm{~km}$ east of Kugluktuk, Nunavut, requiring that 128 passengers be evacuated, which strained emergency systems. ${ }^{1}$ Yet, such events that garner widespread public attention should also serve to highlight persistent gaps in the emergency medical care available to Inuit communities living in the Canadian North, and spur interventions to improve resilience and access to services.

Medical emergencies in Canada's North, particularly those that occur outside of established communities, illustrate some of the most dramatic health disparities experienced in Canada. In the Canadian Arctic, rates of unintentional injury are estimated to be 3.7 times the national average (72.5:100000 v. 19.8:100000), with elevated rates of all-terrain vehicle and snowmobile injuries, drowning and asphyxiation compared with southern Canada (proportionate injury ratios of 1.93 and 1.52 , respectively). ${ }^{2,3}$ Searchand-rescue incidents have more than doubled over the past decade, with a rate of roughly 14.1:1000 noted in Nunavut in 2015, which suggests an increasing burden. ${ }^{4}$

Most of Canada's 60000 Inuit live in one of 53 communities spread along its northern coastline. In these communities, travel and hunting on the land, ice and water are regular activities that are central to well-being, cultural identity and food security. Trips "on the land" can range from day-trips to a cabin by all-terrain vehicle, snowmobile or boat, to multiday trips to harvesting grounds, cultural sites or neighbouring communities. For anyone stranded because of a vehicle breakdown or injured from a fall through the ice, barriers in access to definitive medical care can be life threatening. Of 543 incidents above $55^{\circ} \mathrm{N}$ latitude in 2014 , $20 \%$ of the people involved were either dead or in critical condition on arrival at a health care facility (Figure 1$).{ }^{5}$ Prehospital medical care, however, is almost nonexistent across the region, with no ground advanced life support prehospital care in any of the three territories. Furthermore, only $29 \%$ of communities in the territories have ambulances, most of which are at a firstresponder level. ${ }^{6,7}$ In most locations, definitive medical care

\section{KEY POINTS}

- Wide disparities in both rates of unintentional injury and access to search-and-rescue services and emergency medical care exist between southern and northern Canada.

- Recent high-profile events in the Northwest Passage have drawn attention to the potential for a large-scale disaster in the Canadian Arctic.

- In the emergency medical care available to Inuit communities living in the Canadian North, interventions to improve resilience particularly in the face of the effects of climate change - and access to emergency medical response services are needed.

requires transport in personal vehicles, by snowmobile or by allterrain vehicle to community health centres by volunteers who, at best, have basic first aid knowledge. ${ }^{8-10}$

Although community health centres can treat minor injuries, most do not have the capacity to care for major traumas, which means that aeromedical evacuation to regional hubs or southern hospitals is required.

Climate change is expected to alter the Canadian Arctic profoundly, with the region anticipated to have ice-free summers within the next half century, in addition to increasingly unpredictable storm activity. Environmental changes will affect hazards as sea ice seasons shift, ice thickness changes, iceberg abundance increases and weather becomes more unpredictable. ${ }^{11,12} \mathrm{~A}$ recent case-control study of 202 search and rescues in Nunavut showed a strong link between sea ice, temperature and probability of an incident, ${ }^{4}$ while risks of navigating in poorly charted Arctic waters are well known. ${ }^{1,12}$ It is only a matter of time before a major incident occurs.

In light of current disparities and clear future challenges, it is essential that we take stock of emergency response capacities in the Canadian Arctic and develop robust policies at local, regional and national levels that are adapted to climate change and the pressing health needs of the region. Improved governance and funding, to address gaps in search-and-rescue services and in local capacity for advanced life support prehospital care in the territories, is urgently required. ${ }^{8,9}$ Efforts to prevent incidents and emergencies, also key to addressing health inequalities, will require investment in and collaboration with Inuit communities. Opportunities for intervention 


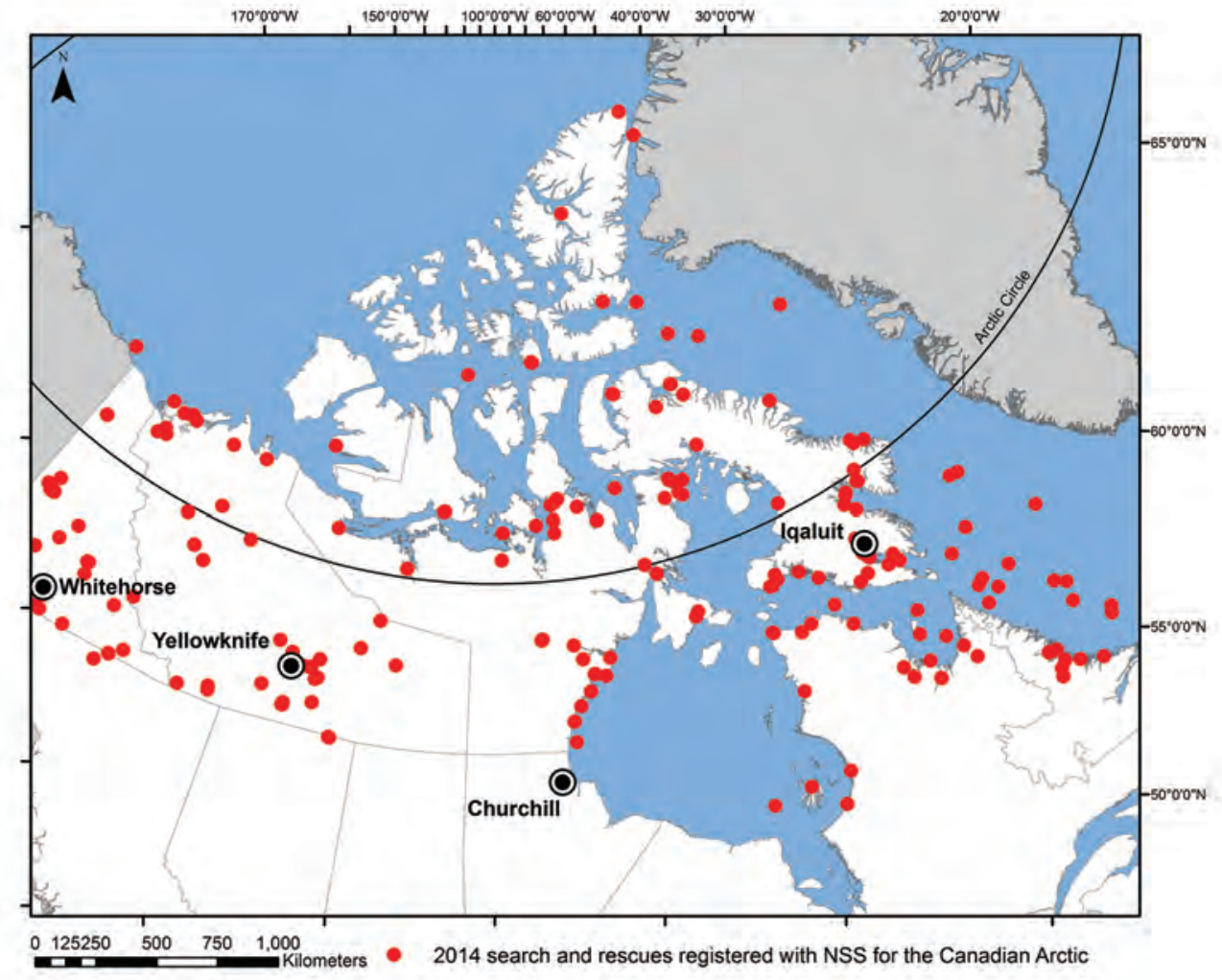

Figure 1: Arctic search and rescues in 2014. Map produced by authors with data from the National Search and Rescue Secretariat (NSS). ${ }^{5}$ Content and data are from the Public Safety Canada Search and Rescue Knowledge Management System and Statistics Canada Digital Boundary files from 2006.

include promotion of intergenerational exchange of traditional knowledge that has long underpinned safe and respectful use of the Arctic environment; removal of barriers to harvesting and land use activities; and evaluation of the use of new technologies for reducing risks associated with land use, including unmanned aerial vehicles and social network solutions. ${ }^{9}$ Such actions would serve to reduce health inequalities between southern and northern Canada, and will enhance communities' resilience into the future.

\section{References}

1. Pincus R. Large-scale disaster response in the Arctic: Are we ready? Arctic Yearbook 2015;234-46.

2. Do MT, Fréchette M, McFaull S, et al. Injuries in the North - analysis of 20 years of surveillance data collected by the Canadian Hospitals Injury Reporting and Prevention Program. Int J Circumpolar Health 2013;72.

3. Health indicators of Inuit Nunagat within the Canadian context: 1994-1998 and 1999-2003. Ottawa: Inuit Tapiriit Kanatami: 2010
4. Clark DG, Ford JD, Berrang-Ford $L$, et al. The role of environmental factors in search and rescue incidents in Nunavut, Canada. Public Health 2016;44-9.

5. Search and Rescue Knowledge Management System (updated 2015). Ottawa: National Search and Rescue Secretariat; 2016. Available: https://sarkms-rssgc.hre -ehr.gc.ca/_layouts/15/SARKMS.SignIn/CustomSignin.aspx (accessed 2016 Nov. 9).

6. Emergency Medical Services. Yukon Government; 2016. Available: www. community.gov.yk.ca/ems/ems.html (accessed 2016 Nov. 9).

7. Ground Ambulance Act - Discussion paper. Northwest Territories Health and Social Services; 2014. Available: www.hss.gov.nt.ca/sites/www.hss.gov.nt.ca/files/ ground-ambulance-discussion-paper.pdf (accessed 2016 Nov. 9).

8. Funston B. Emergency Preparedness in Canada's North: an examination of community capacity. Toronto: Walter \& Duncan Gordon Foundation; 2014.

9. Clark DG, Ford JD, Pearce T, et al. Vulnerability to injuries associated with land-use activities in Nunavut, Canada. Soc Sci Med 2016;169:18-26.

10. National roundtable on Arctic emergency preparedness: report on proceedings. Toronto: Munk-Gordon Arctic Security Program; 2014.

11. Hezel PJ, Fichefet T, Massonnet F. Modeled Arctic sea ice evolution through 2300 in CMIP5 extended RCPs. Cryosphere 2014;8:1195-204.

12. Ford JD, Bell T, Couture NJ. Chapter 5: Persepectives on Canada's North Coast region. In: Lemmen DS, Warren FJ, James TS, et al, editors. Canada's marine coasts in a changing climate. Ottawa: Natural Resources Canada; 2016.

\section{Competing interests: None declared.}

This article has been peer reviewed.

Affiliation: Department of Geography, McGill University, Montréal, Que.

Contributors: Dylan Clark conceived the idea and framing of the article. Both of the authors collaborated on the first draft and revisions of the article, and approved the final version to be published.
Funding: James Ford is supported by an Applied Public Health Chair from the Canadian Institutes of Health Research (CIHR) and ArcticNet. Dylan Clark and James Ford are funded by a CIHR Community-Based Primary health care team grant (grant no. TT6-128271).

Correspondence to: James Ford, james.ford@mcgill.ca 